\title{
Two low-dose bowel-cleansing regimens: efficacy and safety of senna and sodium phosphorus solution for colonoscopy
}

This article was published in the following Dove Press journal:

Patient Preference and Adherence

15 September 2015

Number of times this article has been viewed

\author{
Orhan Kursat Poyrazoglu \\ Mehmet Yalniz \\ Department of Gastroenterology, \\ School of Medicine, Firat University, \\ Elazig, Turkey
}

Background: The aim of the present study was to compare the efficacy, adequacy, side effects, and patient compliance of sodium phosphorus $(\mathrm{NaP})$ and senna solutions when preparing the colon before colonoscopy.

Methods: A total of 137 consecutive patients who were considered for colonoscopy evaluation had randomly received one of two premeditated regimens: $90 \mathrm{~mL}$ of oral $\mathrm{NaP}$ ( $\mathrm{NaP}$ group) or $500 \mathrm{~mL}$ of $1,000 \mathrm{mg}$ of sennosides A and B calcium $+66.6 \mathrm{~g}$ of sorbitol (senna group). Patients' compliance with the bowel-cleansing method was determined using a questionnaire prior to the colonoscopic examination. On the other hand, the adequacy of the bowel-cleansing method was evaluated by the colonoscopist who was blind to the bowel-cleansing regimen used prior to the examination of the colon from the rectum to the cecum.

Results: Nausea and vomiting complaints were seen more frequently in the NaP group than in the senna group ( 47 vs 28 and 31 vs $10 ; P<0.05$ and $P<0.01$, respectively). The response to the question of whether the patients would like to use the same regimen again or not was similar in both groups. The acceptable bowel-cleansing rate was also comparable across both groups. Nevertheless, the number of patients that experienced excellent bowel cleansing in terms of general appraisal of the colonoscopic evaluation was significantly greater in the $\mathrm{NaP}$ group than in the senna group (46 vs $25 ; P<0.001$ ).

Conclusion: Although bowel cleansing was better in the $\mathrm{NaP}$ group, both cleansing regimens were comparable regarding the admissibility of the preparations for the procedure. The senna regimen is, however, superior to the $\mathrm{NaP}$ regimen in terms of application compliance and its side effects, and it may be an effective alternative for cleansing the bowel prior to colonoscopic examination.

Keywords: bowel preparation, colonoscopy, side effect, senna, sodium phosphorus

\section{Introduction}

Colonoscopic examination is the most effective method used to evaluate the colon. It has superior sensitivity and specificity as compared to contrast enema when evaluating mucosal abnormalities in the colon. On the other hand, colonoscopy is a technique that is difficult to perform, and its success depends not only on the colonoscopist's skill but also on the patient's comfort, compliance, and colon cleansing. ${ }^{1-3}$ In this context, adequate cleansing of the bowel (which is a bothersome procedure) must be performed by the patients, and adequate preparation of the bowels is a principal step in the colonoscopic evaluation. Insufficient bowel cleansing either leads the colonoscopist to miss pathological lesions, or it serves as an obstacle to the therapeutic interventions required for the lesions that are found. This situation defers the procedure, and it results in the need to repeat the evaluation.
Correspondence: Orhan Kursat Poyrazoglu

Department of Gastroenterology, School of Medicine, Firat University, 23119

Elazig, Turkey

Tel +904242333555

Fax +90424238 8096

Email okpoyrazoglu@yahoo.com 
In the last several decades, sodium phosphorus ( $\mathrm{NaP})$ and polyethylene glycol electrolyte solutions (PEG-ES) have commonly been used as compounds for bowel cleansing. Although the $\mathrm{NaP}$ solution is better tolerated than the PEG-ES, its ineligibility in patients with concomitant diseases such as renal failure, congestive heart failure, and cirrhosis hampers its extensive utility. ${ }^{4}$

Senna, an antracinon, exerts its action by increasing bowel motility, and it leads to the accumulation of water and electrolytes within the lumen of the colon. Its safety and ease of application are further advantages. Although it is widely used in the treatment of constipation, there is little information about its practice in bowel cleansing. ${ }^{5-7}$

The aim of this study was to compare the efficacy of the senna and $\mathrm{NaP}$ solutions upon bowel cleansing, as well as to investigate patient compliance and cleansing adequacy prior to the colonoscopy procedure in an outpatient population.

\section{Methods}

\section{Study design and population}

The study was designed as randomized controlled investigatorblinded trial. A total of 137 consecutive patients who were admitted to the Gastroenterology Endoscopy Unit of the Firat University School of Medicine (Elazig, Turkey) were randomly allocated to receive either the $\mathrm{NaP}$ or senna solution. The patients were selected if they were adults ( $>18$ years) who were planning to undergo an elective colonoscopic examination. The main indications to perform colonoscopy were screening for cancer, previous polyp history, bleeding, anemia, change in bowel habits, and the presence of inflammatory bowel disease. Two envelopes containing a prescription for the two different bowel-cleansing regimens were prepared for randomization.

Patients with a history of allergy to the senna or NaP solutions; with serious metabolic, renal, and cardiac diseases; those who were pregnant; those with a history of laxative ingestion 1 week prior to the examination; those with a history of colon surgery; those who were admitted with an indication for sigmoidoscopic evaluation; psychotic and bedridden patients; individuals younger than 18 years of age; and those who rejected the procedure were excluded from the study. The patients were described, in detail (both orally and in writing by an experienced staff member), the diet that should be practiced and the bowel-cleansing regimen that should be followed. The patients were advised to eat low-residue foods and to increase the amount of liquids that they consumed during the 3 days prior to their colonoscopy. In addition, the patients were also advised to eat liquid foods after a light breakfast, and not to ingest anything after midnight the day before the colonoscopy. The patients received the senna solution $(500 \mathrm{~mL}, 1,000 \mathrm{mg}$ of sennosides A and B calcium $+66.6 \mathrm{~g}$ of sorbitol) in two divided doses 1 day before the procedure: $250 \mathrm{~mL}$ at $4 \mathrm{pm}$ and $250 \mathrm{~mL}$ at $6 \mathrm{pm}$. The NaP solution (a total of $90 \mathrm{~mL}$ ) was also given in two even doses: half of the solution was ingested 1 day before the procedure at $8 \mathrm{pm}$ and the other half was received at 6 am on the day of the procedure. Blood was collected from all patients before and after the bowel cleansing to determine the changes in electrolytes. The concentrations of sodium, calcium, ionized calcium, phosphorus, and chloride were analyzed in the blood samples. The study was performed according to the Declaration of Helsinki. In addition, approval was obtained from the Firat University School of Medicine Ethics Committee prior to performing the study. Informed consent was also obtained from all of the participants prior to starting the study.

\section{Evaluation of the colon preparation}

First, all the patients were asked about whether or not they adhered to the recommended prescription. Patients were deemed as having adhered to the recommended prescription if they obeyed at least $75 \%$ of the prescribed regimen. The patients' compliance to the bowel-cleansing regimen, as well as any gastrointestinal or other unfavorable symptoms (nausea, vomiting, abdominal pain, and dizziness) induced by these regimens, was assessed, and patients' responses were graded using a four-point scoring system: $1=$ no trouble; $2=$ mild; $3=$ moderate; and $4=$ severe. The following questions were included in the questionnaire that was administered to the patients in this study: "Were you able to complete the prep? (Yes/No). If not, please indicate the amount of prep you were able to drink. (Not able to drink, $1 / 4,2 / 4,3 / 4)$ ". "Would you try the same preparation again if you needed another colonoscopy in the future? (Yes/No)". "Please indicate if any of the following symptoms (nausea, vomiting, abdominal pain, bloating, chest pain, and dizziness) occurred during the prep and rate their severity (no trouble, mild, moderate, severe)".

All of the colonoscopic examinations were performed between 8 am and 12 pm under conscious sedation (midazolam, pethidine $\mathrm{HCl}$ ). After the examination, the investigator scored the difficulty of the colonoscopic evaluation ( $1=$ easy, $2=$ very easy, $3=$ difficult, and $4=$ the procedure cannot be completed). The cleanliness of the colon was also scored for each colonic segment using a validated scale called the Aronchick classification. ${ }^{8,9}$ The patients were allocated into one of two groups based on a general appraisal of the colonoscopic 
evaluation: excellent/good and fairly good/inadequate. The definitions of these categories are as follows: "Excellent", $90 \%$ of the mucosa is visible, mostly liquid feces, and an adequate image is obtained after slight aspiration; "Good", $90 \%$ of the mucosa is visible, mostly liquid feces, and an adequate image is obtained after substantial aspiration; "Fairly good", 90\% of the mucosa is visible, mostly mixed liquid and smooth feces, which could be aspirated or washed; and "Inadequate/requires repreparation", less than $90 \%$ of the mucosa is visible, mostly smooth and solid feces, which cannot be aspirated or washed.

A skilled staff member in the endoscopy unit filled out all of the procedure- and study-related documents before the colonoscopist began the procedure. The patients' demographic and clinical data (age, sex, height, weight, the patient's mobility, and the drugs used), the indication for the colonoscopy, the start time of the procedure, the time to reach the cecum, the total procedure time, the reasons for not being able to reach the cecum, the endoscopic diagnosis, and the interventions performed during the procedure (such as a polypectomy) were recorded. The primary end point was to determine the adequacy of the colon's cleanliness. The secondary end points included comparing the colon-cleansing scores, the number of repeat colonoscopy procedures required, the patients' compliance for each given regimen, and the frequency of the various side effects.

\section{Sampling survey and statistical analysis}

Previous studies pointed out that an excellent and good response rate of $70 \%-90 \%$ was achieved among those individuals who were prescribed the NaP solution. ${ }^{10-12}$ The response rate was between $70 \%$ and $85 \%$ among those individuals who used the senna solution. ${ }^{13-16}$ Therefore, the sampling survey was estimated in light of the published data. A minimum of 124 patients was required for inclusion in this study when a $20 \%$ difference was taken into consideration in terms of acceptable bowel cleansing between the senna and $\mathrm{NaP}$ regimens. This was calculated to account for a $5 \%$ statistical type 1 error and $80 \%$ statistical power. Distributions of the data were evaluated with the Shapiro-Wilk test and QQ plot. The chi-squared test, paired-samples $t$-test, and independent-samples $t$-test were used in appropriate situations. The data were presented as the mean and standard deviation. $P$-values $<0.05$ were considered significant.

\section{Results}

A total of 137 patients were enrolled in this study. Nine patients (four from the senna group, five from the $\mathrm{NaP}$ group) were excluded from the study. The reasons for exclusion were as follows: seven patients (three from the senna group and four from the $\mathrm{NaP}$ group) did not adequately perform the bowel-cleansing regimen; moreover, two did not complete the questionnaire form. As such, 128 patients (62 in the senna group, 66 in the $\mathrm{NaP}$ group) were included in the study, regardless of whether the colonoscopy procedure was completed or not. The demographic characteristics and colonoscopic features of the patients were comparable in the two study groups, and these details are shown in Table 1 . The cecum could not be reached in only four $(6.5 \%)$ and seven $(10.6 \%)$ patients from the senna and $\mathrm{NaP}$ groups, respectively. The cecum could not be reached in patients 2 and 1, in the senna and $\mathrm{NaP}$ groups, respectively, for technical reasons and patient intolerance, nor could it be reached in patients 3 and 5, respectively, due to inadequate bowel cleansing. Nausea and vomiting symptoms were significantly less frequent in the senna group than in the NaP group $(P<0.05$ and $P<0.01$, respectively). There was no significant difference observed with respect to the other side effects (Table 2). The patients' responses to the question of whether or not they would like to use the same regimen in the future that they performed for the current colonoscopy were comparable between the two study groups (66.7\% vs 79\%). There was also no significant difference between the groups regarding whether or not the colonic cleansing was acceptable (Table 3 ). However, the number of patients with excellent bowel cleansing according to the general appraisal of colonoscopic evaluation was significantly higher in the $\mathrm{NaP}$ regimen group than in the senna group (46 [78\%] vs 25 [43.1\%], respectively; $P<0.001$ ). Furthermore, the evaluation quality of the cecum was also better in the NaP group than in the senna group (42 [72.1\%] vs 25 [43.1\%], respectively; $P<0.01$ ).

Comparisons of systolic/diastolic blood pressure levels and biochemical changes are shown in Table 4. Following the colon preparation regimen, both groups had an average decrease of 8-10 $\mathrm{mmHg}$ in both systolic and diastolic blood pressure, which was significant; however, there was no difference between the groups. Serum sodium levels increased in the $\mathrm{NaP}$ group $(P<0.001)$ after the preparation, but it remained unchanged in the senna group. After the procedure, the serum potassium levels decreased in both the groups; the difference reached statistical significance in the NaP group $(P=0.001)$. Serum chloride levels increased following the procedure in both the groups; the difference was significant within the groups $(P=0.001)$, and it was also significant between the groups $(P<0.05)$. Total and ionized calcium levels decreased in the senna and $\mathrm{NaP}$ groups $(P=0.001)$, 
Table I Demographic and colonoscopic characteristics of the patients

\begin{tabular}{|c|c|c|c|}
\hline Patient characteristics & Senna $(n=62)$ & $\mathrm{NaP}(n=66)$ & $P$-value \\
\hline Age (years) & $49.8 \pm 14.8$ & $47.7 \pm 14.3$ & $0.4 \mid 4$ \\
\hline Sex (male/female) & $37 / 25$ & $37 / 29$ & 0.722 \\
\hline BMI $\left(\mathrm{kg} / \mathrm{m}^{2}\right)$ & $25.3 \pm 3.5$ & $25.1 \pm 3.4$ & 0.807 \\
\hline Time to reach cecum (minutes) & $8.2 \pm 4.1$ & $8.1 \pm 3.9$ & 0.879 \\
\hline Total procedure time (minutes) & $19.3 \pm 8.1$ & $18.8 \pm 5.8$ & 0.695 \\
\hline Number of incomplete colonoscopy procedures & 4 & 7 & 0.533 \\
\hline Technical difficulty & & & 0.667 \\
\hline Easy/fairly easy (\%) & $53(85.5)$ & $52(78.8)$ & \\
\hline Difficult/incomplete (\%) & $9(14.5)$ & $14(21.2)$ & \\
\hline Cecum intubation rate (\%) & $58(91.9)$ & $59(89.4)$ & 0.533 \\
\hline Colonoscopy indication & & & 0.730 \\
\hline Cancer screening/polyp history & 8 & 9 & \\
\hline Bleeding/anemia history & 15 & 11 & \\
\hline Change in bowel habit & 24 & 26 & \\
\hline Inflammatory bowel diseases & 3 & 2 & \\
\hline Other & 12 & 18 & \\
\hline Colonoscopic diagnosis & & & 0.901 \\
\hline Normal & 29 & 29 & \\
\hline Polyp & 13 & 17 & \\
\hline Hemorrhoid-fissure & 7 & 6 & \\
\hline Colon cancer & 1 & 1 & \\
\hline Inflammatory bowel diseases & 3 & I & \\
\hline Other & 5 & 5 & \\
\hline
\end{tabular}

Abbreviations: NaP, sodium phosphorus; BMI, body mass index.

but there was no difference between the groups. Inorganic phosphorus levels were clearly increased in the NaP group $(P=0.001)$.

\section{Discussion}

Colonoscopic examination is superior to the other screening tests for detecting the presence of colorectal cancer and its precancerous lesions. In addition to its relevance in diagnosis and treatment, colonoscopies are also cheaper than the other screening modalities. ${ }^{1-3,17}$ Its most undesirable feature, however, is that it requires cleansing of the bowel. Furthermore, some patients cannot accomplish bowel cleansing due to the side effects of the drugs used for this purpose. Hence, the colon cannot be visualized efficiently when the bowel is inadequately cleansed. This disadvantage results in the need

Table 2 Comparison of compliance to the colonoscopic preparation methods

\begin{tabular}{lllll}
\hline Complaints & $\begin{array}{l}\text { No trouble } \\
\text { (Sen/NaP) }\end{array}$ & $\begin{array}{l}\text { Mild } \\
\text { (Sen/NaP) }\end{array}$ & $\begin{array}{l}\text { Moderate } \\
\text { (Sen/NaP) }\end{array}$ & $\begin{array}{l}\text { Severe } \\
\text { (Sen/NaP) }\end{array}$ \\
\hline Nausea* & $34 / 19$ & $23 / 32$ & $3 / 11$ & $2 / 4$ \\
Vomiting** & $52 / 35$ & $7 / 22$ & $2 / 6$ & $1 / 3$ \\
Abdominal pain & $40 / 37$ & $14 / 19$ & $6 / 8$ & $2 / 2$ \\
Dizziness & $55 / 52$ & $6 / 12$ & -12 & $1 /-$ \\
Headache & $52 / 54$ & $8 / 8$ & $1 / 3$ & $1 / 1$ \\
\hline
\end{tabular}

Notes: $* P<0.05, * * P<0.01$; senna vs $\mathrm{NaP}$.

Abbreviations: Sen, senna; NaP, sodium phosphorus. to repeat the procedure; it also increases the risks related to the procedure, and polyps are often overlooked. ${ }^{18-20}$ Thus, the adequate and convenient application of a given bowelcleansing regimen increases the likelihood of a complete and successful colonoscopic examination.

PEG-ES and NaP preparations are commonly used colonoscopic cleansing regimens. However, studies continue to seek alternative bowel-cleansing methods due to compliance and safety issues. The $\mathrm{NaP}$ regimens draw particular attention, as they are effective at lower concentrations and are available in the form of tablets; ${ }^{8,21-23}$ however, they do cause hyperphosphatemia and hypocalcemia. ${ }^{24,25}$ Additionally, numerous colonoscopists do not take into consideration the potential renal, hepatic, and cardiovascular risks of these agents. $^{26}$

Table 3 Evaluation of the colonoscopic examination

\begin{tabular}{lllll}
\hline Parameters & $\begin{array}{l}\text { Excellent } \\
\text { (Sen/NaP) }\end{array}$ & $\begin{array}{l}\text { Good } \\
\text { (Sen/NaP) }\end{array}$ & $\begin{array}{l}\text { Fairly good } \\
\text { (Sen/NaP) }\end{array}$ & $\begin{array}{l}\text { Inadequate } \\
\text { (Sen/NaP) }\end{array}$ \\
\hline Rectum & $49 / 50$ & $3 / 5$ & $6 / 3$ & $2 / 2$ \\
Sigmoid colon & $45 / 51$ & $4 / 5$ & $8 / 1$ & $3 / 3$ \\
Descending colon & $51 / 47$ & $3 / 6$ & $3 / 4$ & $2 / 3$ \\
Transverse colon & $45 / 49$ & $7 / 4$ & $2 / 4$ & $4 / 2$ \\
Ascending colon & $34 / 47$ & $8 / 3$ & $10 / 4$ & $6 / 5$ \\
Cecum* & $25 / 42$ & $5 / 6$ & $8 / 3$ & $20 / 8$ \\
\hline
\end{tabular}

Notes: $* P<0.01$; senna vs $\mathrm{NaP}$

Abbreviations: Sen, senna; NaP, sodium phosphorus. 
Table 4 Parameters determined before and after the colonoscopic examination

\begin{tabular}{|c|c|c|c|c|}
\hline \multirow[t]{2}{*}{ Parameters } & \multicolumn{2}{|c|}{ Senna $(n=62)$} & \multicolumn{2}{|c|}{$\mathrm{NaP}(\mathrm{n}=66)$} \\
\hline & Before & After & Before & After \\
\hline Blood pressure systolic (mmHg) & $120.5 \pm 22$ & $112 \pm 25.5^{\# \#}$ & $127 \pm 25$ & $116 \pm 23^{\# \#}$ \\
\hline Diastolic (mmHg) & $76 \pm 17.6$ & $70.7 \pm 12.8^{\#}$ & $77.9 \pm 12.9$ & $71.7 \pm 11.8^{\#}$ \\
\hline Sodium (mEq/L) & $138.8 \pm 2.7$ & $138.7 \pm 3.1$ & $139.1 \pm 2.2$ & $|4| . \mid \pm 3.8^{* * * \#}$ \\
\hline Potassium (mEq/L) & $4.3 \pm 0.4$ & $4.1 \pm 0.6$ & $4.3 \pm 0.4$ & $3.9 \pm 0.4^{*}$ \\
\hline Chloride (mEq/L) & $105.1 \pm 3.5$ & $106.3 \pm 3.4^{\#}$ & $105.4 \pm 3$ & $107.8 \pm 3.4^{*}$ \\
\hline Calcium (mEq/L) & $9.4 \pm 0.6$ & $9.3 \pm 0.7^{\# \#}$ & $9.5 \pm 0.5$ & $8.8 \pm 0.5 * * \ldots$ \\
\hline lonized calcium (mmol/L) & $\mathrm{I} \pm 0 . \mathrm{I}$ & $0.7 \pm 0.2^{\#}$ & $\mathrm{I} \pm 0 . \mathrm{I}$ & $0.8 \pm 0.2^{\#}$ \\
\hline Inorganic phosphorus (mEq/L) & $3.5 \pm 0.7$ & $3.9 \pm I^{\#}$ & $3.5 \pm 0.7$ & $6.3 \pm 1.9 * * \ldots$ \\
\hline
\end{tabular}

Notes: ${ }^{*} P<0.05,{ }^{*} * P<0.00$ I, senna vs $\mathrm{NaP} ;{ }^{\#} P=0.0$ I, senna (before vs after); ${ }^{\#} P=0.00 \mathrm{I}$, senna (before vs after) and $\mathrm{NaP}$ (before vs after). Abbreviation: $\mathrm{NaP}$, sodium phosphorus.

Stimulant laxatives have commonly been used in the past as enemas for bowel preparation. ${ }^{27-32}$ Nevertheless, there are limited data about their application as bowel-cleansing agents. ${ }^{33,34}$ The application of senna alone or combined with other laxatives is superior to the PEG and $\mathrm{NaP}$ solutions, and it is associated with comparable side effects and tolerance levels. ${ }^{7,35-38}$ However, some studies reported the opposite results and indicated that senna is insufficient for bowel preparation and is also less tolerable. . $7,33,39,40^{\text {On the }}$ other hand, acceptable bowel cleansing was similar in both groups, although excellent bowel cleansing was encountered more frequently in the NaP group. In addition, we could not definitively conclude whether sennoside or sorbitol alone had such an effect on acceptable bowel preparation. Furthermore, bowel cleansing in the cecum was also superior in the $\mathrm{NaP}$ group. This situation might be related to the amount of time elapsed from the application of the bowel-cleansing preparation to the commencement of the procedure.

Tolerance to the given regimen and optimal compliance of the patients to the dosing used play a crucial role in successful bowel cleansing. ${ }^{41}$ In the present study, the most frequently encountered symptoms in both groups were nausea and vomiting. Nevertheless, these symptoms were found to be significantly more frequent in the $\mathrm{NaP}$ group than in the senna group. Although it was advised that the patients ingest the $\mathrm{NaP}$ with a fruit juice, the difference between the groups might be the result of the better taste of the senna solution. Other symptoms were comparable in both groups. Although the side effects were different between the two groups, the patients' responses to the question of whether they would like to receive the same agent again for future colonoscopies were similar in both groups.

The NaP solution is a popular bowel-cleansing regimen. However, it is contraindicated (or must be used with caution) in older patients, those with renal failure or cardiovascular disease, those with insufficient bowel cleansing, and those with bowel motility deficiency. $\mathrm{NaP}$ can also lead to serious electrolyte abnormalities. ${ }^{42,43}$ On the other hand, senna is not frequently used for bowel cleansing. Presumably, its side effects such as hepatitis, cachexia, tetany, clubbing, and hypertrophic osteoarthropathy, as well as studies reporting its inadequate efficiency, hampered its utility in this field. ${ }^{44} 48$ In addition, the senna regimen did not only contain sennoside as the active ingredient, but it also included sorbitol. However, we did not see any possible side effects associated with sorbitol, including ulcer, intestinal perforation, or bowel necrosis, in our patients. ${ }^{49-51}$ In this study, NaP caused significant changes in the levels of all electrolytes, and the findings corroborated those of previous studies. ${ }^{24-26,43}$ Additionally, significant changes in calcium, inorganic phosphorus, and chloride levels were also seen in patients who used the senna solution. This might be related to the dose used for the bowel-cleansing regimen.

\section{Conclusion}

Senna does not seem to be as effective as the $\mathrm{NaP}$ solution for bowel cleansing. However, further studies investigating the amount of time elapsed from the application of the bowelcleansing regimen to the commencement of the colonoscopic examination, as well as the dose of the regimen used, may elicit demonstrations of efficacy. Nonetheless, senna may be considered as an alternative bowel-cleansing regimen due to the fact that it results in fewer side effects when compared to the NaP solution.

\section{Disclosure}

The authors report no conflicts of interest in this work.

\section{References}

1. Winawer SJ, Stewart ET, Zauber AG, et al. A comparison of colonoscopy and double-contrast barium enema for surveillance after polypectomy. N Engl J Med. 2000;342(24):1766-1772. 
2. Vijan S, Hwang EW, Hofer TP, Hayward RA. Which colon cancer screening test? A comparison of costs, effectiveness, and compliance. Am J Med. 2001;111:593-601.

3. Lichtenstein GR, Cohen LB, Uribarri J. Review article: bowel preparation for colonoscopy - the importance of adequate hydration. Aliment Pharmacol Ther. 2007;26(5):633-641.

4. Wexner SD, Beck DE, Baron TH, et al. A consensus document on bowel preparation before colonoscopy: prepared by a task force from the American Society of Colon and Rectal Surgeons (ASCRS), the American Society for Gastrointestinal Endoscopy (ASGE), and the Society of American Gastrointestinal and Endoscopic Surgeons (SAGES). Gastrointest Endosc. 2006;63(7):894-909.

5. Leng-Peschlow E. Sennoside-induced secretion and its relevance for the laxative effect. Pharmacology. 1993;47(suppl 1):14-21.

6. Unal S, Doğan UB, Oztürk Z, Cindoruk M. A randomized prospective trial comparing 45 and $90-\mathrm{mL}$ oral sodium phosphate with X-Prep in the preparation of patients for colonoscopy. Acta Gastroenterol Belg. 1998; 61(3):281-284.

7. Radaelli F, Meucci G, Imperiali G, et al. High-dose senna compared with conventional PEG-ES lavage as bowel preparation for elective colonoscopy: a prospective, randomized, investigator-blinded trial. $\mathrm{Am}$ J Gastroenterol. 2005;100(12):2674-2680.

8. Aronchick CA, Lipshutz WH, Wright SH, Dufrayne F, Bergman G. A novel tableted purgative for colonoscopic preparation: efficacy and safety comparisons with Colyte and Fleet Phospho-Soda. Gastrointest Endosc. 2000;52(3):346-352.

9. Aronchick CA, Lipshutz WH, Wright SH, DuFrayne F, Bergman G. Validation of an instrument to assess colon cleansing (abstract). Am J Gastroenterol. 1999;94:2667.

10. Cohen SM, Wexner SD, Binderow SR, et al. Prospective, randomized, endoscopic-blinded trial comparing precolonoscopy bowel cleansing methods. Dis Colon Rectum. 1994;37:689-696.

11. Marshall JB, Pineda JJ, Barthel JS, King PD. Prospective, randomized trial comparing sodium phosphate solution with polyethylene glycolelectrolyte lavage for colonoscopy preparation. Gastrointest Endosc. 1993;39:631-634.

12. Juluri R, Eckert G, Imperiale TF. Meta-analysis: randomized controlled trials of 4-L polyethylene glycol and sodium phosphate solution as bowel preparation for colonoscopy. Aliment Pharmacol Ther. 2010; 32(2):171-181.

13. Hangartner PJ, Munch R, Meier J, Ammann R, Buhler H. Comparison of three colon cleansing methods: evaluation of a randomized clinical trial with 300 ambulatory patients. Endoscopy. 1989;21:272-275.

14. Borkje B, Pedersen R, Lund GM, Enehaug JS, Berstad A. Effectiveness and acceptability of three bowel cleansing regimens. Scand J Gastroenterol. 1991;26:162-166.

15. Chilton AP, O'Sullivan M, Cox MA, Loft DE, Nwokolo CU. A blinded, randomized comparision of a novel, low-dose, triple regimen with fleet phospho-soda: a study of colon cleanliness, speed and success of colonoscopy. Endoscopy. 2000;32:37-41.

16. Arezzo A. Prospective randomized trial comparing bowel cleaning preparations for colonoscopy. Surg Laparosc Endosc Percutan Tech. 2000; $10: 215-217$

17. Lieberman DA, Weiss DG, Bond JH, Ahnen DJ, Garewal H, Chejfec G. Use of colonoscopy to screen asymptomatic adults for colorectal cancer. N Engl J Med. 2000;343:162-168.

18. Rex DK, Imperiale TF, Latinovich DR, Bratcher LL. Impact of bowel preparation on efficiency and cost of colonoscopy. Am J Gastroenterol. 2002;97:1696-1700.

19. Harewood GC, Sharma VK, de Garmo P. Impact of colonoscopy preparation quality on detection of suspected colonic neoplasia. Gastrointest Endosc. 2003;58:76-79.

20. Froehlich F, Wietlisbach V, Gonvers J-J, Burnand B, Vader J-P. Impact of colonic cleansing on quality and diagnostic yield of colonoscopy: the European Panel of Appropriateness of Gastrointestinal Endoscopy European multicenter study. Gastrointest Endosc. 2005;61:378-384.
21. DiPalma JA, Wolff BG, Meagher A, Cleveland MvB. Comparison of reduced volume versus four liters sulfate-free electrolyte lavage solutions for colonoscopy colon cleansing. Am J Gastroenterol. 2003;98: 2187-2191.

22. Marshall JB, Pineda JJ, Barthel JS, King PD. Prospective, randomized trial comparing sodium phosphate solution with polyethylene glycolelectrolyte lavage for colonoscopy preparation. Gastrointest Endosc. 1993;39(5):631-634.

23. Vanner SJ, MacDonald PH, Paterson WG, Prentice RS, Da Costa LR, Beck IT. A randomized prospective trial comparing oral sodium phosphate with standard polyethylene glycol-based lavage solution (Golytely) in the preparation of patients for colonoscopy. Am J Gastroenterol. 1990;85(4):422-427.

24. Curran MP, Plosker GL. Oral sodium phosphate solution: a review of its use as a colorectal cleanser. Drugs. 2004;64:1697-1714.

25. DiPalma JA, Buckley SE, Warner BA, Culpepper RM. Biochemical effects of oral sodium phosphate. Dig Dis Sci. 1996;41(4):749-753.

26. Chan A, Depew W, Vanner S. Use of oral sodium phosphate colonic lavage solution by Canadian colonoscopists: pitfalls and complications. Can J Gastroenterol. 1997;11(4):334-338.

27. Hookey LC, Depew WT, Vanner SJ. A prospective randomized trial comparing low-dose oral sodium phosphate plus stimulant laxatives with large volume polyethylene glycol solution for colon cleansing. Am J Gastroenterol. 2004;99:2217-2222.

28. Hangartner PJ, Munch R, Meier J, Ammann R, Bühler H. Comparison of three colon cleansing methods: evaluation of a randomized clinical trial with 300 ambulatory patients. Endoscopy. 1989;21:272-275.

29. Afridi SA, Barthel JS, King PD, Pineda JJ, Marshall JB. Prospective, randomized trial comparing a new sodium phosphatebisacodyl regimen with conventional PEG-ES lavage for outpatient colonoscopy preparation. Gastrointest Endosc. 1995;41:485-489.

30. Adams WJ, Meagher AP, Lubowski DZ, King DW. Bisacodyl reduces the volume of polyethylene glycol solution required for bowel preparation. Dis Colon Rectum. 1994;37:229-233.

31. Borkje B, Pedersen R, Lund GM, Enehaug JS, Berstad A. Effectiveness and acceptability of three bowel cleansing regimens. Scand J Gastroenterol. 1991;26:162-166.

32. Rasmussen M, Bohlbro K, Qvist N. Oral sodium phosphate compared with water enemas combined with bisacodyl as bowel preparation for elective colonoscopy. Scand J Gastroenterol. 2003;38(10):1090-1094.

33. Arezzo A. Prospective randomized trial comparing bowel cleaning preparations for colonoscopy. Surg Laparosc Endosc Percutan Tech. 2000; $10: 215-217$

34. Yenidogan E, Okan I, Kayaoglu HA, et al. Same-day colonoscopy preparation with Senna alkaloids and bisacodyl tablets: a pilot study. World J Gastroenterol. 2014;20(41):15382-15386.

35. Kositchaiwat S, Suwanthanmma W, Suvikapakornkul R, Tiewthanom V, Rerkpatanakit P, Tinkornrusmee C. Comparative study of two bowel preparation regimens for colonoscopy: senna tablets vs sodium phosphate solution. World J Gastroenterol. 2006;12(34):5536-5539.

36. Farca Belsaguy A, Fernández Castro E, Presenda Miller F. Comparative study of the use of sennoside A and B vs polyethylene glycol and electrolytes in anterograde preparation of the colon. Rev Gastroenterol Mex. 1999;64(2):85-88.

37. Chilton AP, O'Sullivan M, Cox MA, Loft DE, Nwokolo CU. A blinded, randomized comparison of a novel, low-dose, triple regimen with fleet phospho-soda: a study of colon cleanliness, speed and success of colonoscopy. Endoscopy. 2000;32:37-41.

38. Valverde A, Hay JM, Fingerhut A, et al. Senna vs polyethylene glycol for mechanical preparation the evening before elective colonic or rectal resection: a multicenter controlled trial. French Association for Surgical Research. Arch Surg. 1999;134:514-519.

39. Amato A, Radaelli F, Paggi S, Terruzzi V. Half doses of PEG-ES and senna vs high-dose senna for bowel cleansing before colonoscopy: a randomized, investigator-blinded trial. Am J Gastroenterol. 2010; 105(3):675-681. 
40. Dahshan A, Lin CH, Peters J, Thomas R, Tolia V. A randomized, prospective study to evaluate the efficacy and acceptance of three bowel preparations for colonoscopy in children. Am J Gastroenterol. 1999;94:3497-3501.

41. Ness RM, Manam R, Hoen H, Chalasani N. Predictors of inadequate bowel preparation for colonoscopy. Am J Gastroenterol. 2001;96(6):1797-1802.

42. Curran MP, Plosker GL. Oral sodium phosphate solution: a review of its use as a colorectal cleanser. Drugs. 2004;64:1697-1714.

43. Ainley EJ, Winwood PJ, Begley JP. Measurement of serum electrolytes and phosphate after sodium phosphate colonoscopy bowel preparation: an evaluation. Dig Dis Sci. 2005;50(7):1319-1323.

44. Marks GB, Salome CM, Woolcock AJ. Asthma and allergy associated with occupational exposure to ispaghula and senna products in a pharmaceutical work force. Am Rev Respir Dis. 1991;144:1065-1069.

45. Beuers U, Spengler U, Pape GR. Hepatitis after chronic abuse of senna. Lancet. 1991;337:372-373.
46. Armstrong RD, Crisp AJ, Grahame R, Woolf DL. Hypertrophic osteoarthropathy and purgative abuse. Br Med J (Clin Res Ed). 1981; 282:1836.

47. Levine D, Goode AW, Wingate DL. Purgative abuse associated with reversible cachexia, hypogammaglobulinaemia, and finger clubbing. Lancet. 1981;1:919-920.

48. Prior J, White I. Tetany and clubbing in patient who ingested large quantities of senna. Lancet. 1978;2:947.

49. lbeldawi M, Gaur V, Weber L. Kayexalate-induced colonic ulcer. Gastroenterol Rep (Oxf). 2014;2(3):235-236.

50. McGowan CE, Saha S, Chu G, Resnick MB, Moss SF. Intestinal necrosis due to sodium polystyrene sulfonate (Kayexalate) in sorbitol. South Med J. 2009;102(5):493-497.

51. Trottier V, Drolet S, Morcos MW. Ileocolic perforation secondary to sodium polystyrene sulfonate in sorbitol use: a case report. Can J Gastroenterol. 2009;23(10):689-690.

\section{Publish your work in this journal}

Patient Preference and Adherence is an international, peer-reviewed, open access journal that focuses on the growing importance of patient preference and adherence throughout the therapeutic continuum. Patient satisfaction, acceptability, quality of life, compliance, persistence and their role in developing new therapeutic modalities and compounds to optimize clinical outcomes for existing disease states are major areas of interest for the journal. This journal has been accepted for indexing on PubMed Central. The manuscript management system is completely online and includes a very quick and fair peer-review system, which is all easy to use. Visit http://www. dovepress.com/testimonials.php to read real quotes from published authors.

Submit your manuscript here: http://www.dovepress.com/patient-preference-and-adherence-journal 